\title{
Effects of pig follicular fluid on maturation of pig oocytes in vitro and on their subsequent fertilizing and developmental capacity in vitro
}

\author{
M. Yoshida, Y. Ishizaki, H. Kawagishi, K. Bamba and Y. Kojima \\ Faculty of Agriculture, Shizuoka University, Shizuoka 422, Japan
}

\begin{abstract}
Summary. This study examines the effects of pig follicular fluid on the maturation of pig oocytes and on their subsequent fertilizing and developmental capacity in vitro. The addition of pig follicular fluid or its fractions obtained by ultrafiltration, gel filtration and ion-exchange chromatography to maturation medium significantly increased the rates of nuclear maturation, normal fertilization and normal cleavage of pig oocytes after fertilization in vitro: the rates of normal fertilization and cleavage were 2-4 times higher than those in the control medium. The efficacy of pig follicular fluid was lost after heating at $56^{\circ} \mathrm{C}$ for $30 \mathrm{~min}$, whereas no significant decrease in activity was observed after defatting. In addition, the effective component(s) was partially purified by ultrafiltration, gel filtration and ion-exchange chromatography: the activity was observed in the fraction (UF2; $M_{\mathrm{r}} 10000-20000$ ) obtained by ultrafiltration. Activity was found in the first fraction (G1) obtained by gel filtration of UF2. Among three fractions obtained by ion-exchange chromatography of $\mathrm{G} 1$, only the third fraction had the activity. The results indicate that pig follicular fluid contains an acidic substance(s) $\left(M_{\mathrm{r}} 10000-200000\right)$ that promotes oocyte maturation.
\end{abstract}

Keywords: follicular fluid; maturation; fertilization; development; pig; oocytes

\section{Introduction}

Study of the cellular and molecular factors operating during oocyte maturation and fertilization provide the basis for defining conditions for production of embryos in vitro and for their possible application in basic research and animal breeding.

Pig oocytes have been shown to mature, fertilize and develop in vitro (Matiolli et al., 1989; Nagai et al., 1990; Yoshida et al., 1990). However, the occurrence of abnormal maturation and fertilization, e.g. heterogeneous maturation of oocytes (Sato et al., 1978; Yoshida et al., 1989), chromosomal abnormality (McGaughey \& Polge, 1971), polyspermy and polygyny (Yoshida et al., 1990 ) is higher in oocytes matured in vitro than in oocytes matured in vivo.

However, mammalian oocytes are bathed in follicular fluid during maturation and pig follicular fluid has been shown to inhibit oocyte maturation (Tsafriri \& Channing, 1975; Stone et al., 1978; Tsafriri et al., 1982). However, Westergaard et al. (1984) reported that human follicular fluid contained a substance that induced meiosis. Moreover, the addition of pig follicular fluid to maturation medium promoted maturation and fertilization of mouse (Eppig \& Schroeder, 1986) and pig oocytes (Naito et al., 1988) in vitro.

The objective of this study was to examine the effects of pig follicular fluid on the maturation of pig oocytes and their subsequent fertilizing and developmental capacity in vitro. 


\section{Materials and Methods}

Methods for in vitro maturation and fertilization of oocytes were based on those described by Yoshida et al. (1990).

\section{Collection of oocytes and pig follicular fluid}

Ovaries were collected from prepubertal gilts at a local abattoir and transported to the laboratory in $0.9 \%(\mathrm{w} / \mathrm{v})$ $\mathrm{NaCl}$ containing $100 \mathrm{mg}$ kanamycin sulfate $1^{-1}$ (Meiji Seika, Tokyo, Japan) at $35^{\circ} \mathrm{C}$. Within $2 \mathrm{~h}$ of slaughter, the content of follicles ( $2-5 \mathrm{~mm}$ diameter) were recovered by aspiration, using a 21 -gauge needle (Terumo Co., Tokyo, Japan) and a $5 \mathrm{ml}$ disposable syringe (Nipro, Osaka, Japan). The oocyte-cumulus complexes were gathered from the follicular contents and washed twice with Medium PBI (Whittingham, 1971) and the maturation medium, respectively. Only oocytes possessing a compact cumulus mass and evenly granulated ooplasm were selected for the experiments. After removal of oocytes, pig follicular fluid was pooled and centrifuged to remove granulosa and blood cells ( $1500 \mathrm{~g}$ for $30 \mathrm{~min}$ at room temperature). Cell-free pig follicular fluid was filtered with $0.8 \mu \mathrm{m}, 0.45 \mu \mathrm{m}$ and $0.2 \mu \mathrm{m}$ membrane filters (Advantec Toyo Co., Tokyo, Japan), respectively, and stored at $-20^{\circ} \mathrm{C}$ for several weeks before fractionation.

\section{Preparation of spermatozoa}

The sperm-rich fractions of ejaculates were obtained from two Large White boars using the gloved-hand method. Spermatozoa were washed three times with $0.9 \%(\mathrm{w} / \mathrm{v}) \mathrm{NaCl}$ containing $100 \mathrm{mg} \mathrm{BSA}^{-1}$ (Sigma Chemical Co., St Louis, MO, USA) and $100 \mathrm{mg}$ kanamycin sulphate $1^{-1}$. Washed spermatozoa were subsequently diluted to $2 \times 10^{8}$ cells $\mathrm{ml}^{-1}$ in the sperm preincubation medium and incubated for $4 \mathrm{~h}$ at $37^{\circ} \mathrm{C}$ in a tightly capped test-tube.

\section{Heating and defatting of pig follicular fluid}

Pooled pig follicular fluid was divided into aliquots and heated at $56^{\circ} \mathrm{C}$ for $30 \mathrm{~min}$ in a water bath. For preparation of defatted pig follicular fluid, it was partitioned between ethyl acetate (Wako Pure Chemical Industries, Ltd, Tokyo, Japan) and an aqueous layer and then the aqueous layer was concentrated in vacuo and lyophilized. Pooled pig follicular fluid was ultrafiltered with a UK-200 (Advantec: $M_{\mathrm{r}}>200000$ ) and a PM-10 membrane filter (Amicon, Lexington, KY, USA: $M_{\mathrm{r}} 10000$ ) and divided into three fractions: (i) concentrate with UK-200 (UF1, $M_{\mathrm{r}}>200000$ ) (ii) concentrate with PM-10 of filtrate with UK-200 (UF2, $10000<M_{\mathrm{r}}<200000$ ), and (iii) filtrate with PM-10 (UF3, $\left.M_{\mathrm{r}}<10000\right)$. The fraction obtained by ultrafiltration (UF2) was directly applied to a column $(200 \times 900 \mathrm{~mm})$ of Toyopearl 55S (Tosoh Co., Tokyo, Japan: $1000<M_{\mathrm{r}}<700000$ ) equilibrated with Dulbecco's phosphatebuffered saline. Fractions $(1.5 \mathrm{ml})$ were monitored by absorbance at $280 \mathrm{~nm}$ and divided into six fractions (Gl-G6; Fig. 1). Fractions were then pooled and concentrated by ultrafiltration using a PM-10 membrane filter. The fraction obtained by gel filtration (G1) was applied to a column $(200 \times 900 \mathrm{~mm})$ of DEAE-Toyopearl (Tosoh) after equilibration with starting buffer $\left(10 \mathrm{mmol}\right.$ phosphate buffer $\left.\mathrm{I}^{-1}, \mathrm{pH} 6 \cdot 1\right)$ and eluted by applying a linear salt gradient $\left(0.0-0.5 \mathrm{~mol} \mathrm{NaCl}{ }^{-1}\right)$. Fractions $(2.0 \mathrm{ml})$ were monitored by absorbance at $280 \mathrm{~nm}$ and divided into three fractions (DA1-DA3; Fig. 2).

Ultrafiltration, gel filtration and ion-exchange chromatography were carried out at $4^{\circ} \mathrm{C}$. Freeze-dried pig follicular fluid and pig follicular fluid fractions obtained by ultrafiltration were diluted to the original volume of pig follicular fluid in distilled water and fractions obtained by gel filtration and ion-exchange chromatography were diluted to the original volume obtained by ultrafiltration with UK-200 in distilled water. The treated pig follicular fluid fractions were sterilized with $0.2 \mu \mathrm{m}$ membrane filter and stored at $-20^{\circ} \mathrm{C}$ until use.

\section{Maturation, fertilization and culture in vitro}

In all experiments, oocytes were cultured in maturation medium supplemented with or without pig follicular fluid and with or without fractions of pig follicular fluid. Before insemination oocytes (10-15) were transferred to a drop of maturation medium $(0.2 \mathrm{ml})$ in a polystyrene dish $(35 \mathrm{~mm}$ : Becton Dickinson Labware, Oxnard, CA, USA) and cultured for $36 \mathrm{~h}$. After incubation, cumulus expansion was determined by an inverted microscope (Olympus Co., Tokyo, Japan). Oocytes (25-35) were then transferred to fertilization medium $(2.0 \mathrm{ml})$ covered with paraffin oil (Nakarai Tesque, Inc., Kyoto, Japan). The spermatozoa were first diluted to $2 \times 10^{7} \mathrm{cells}^{-1}$ and then introduced into the fertilization medium to a final concentration of $5 \times 10^{5}$ cells $\mathrm{ml}^{-1}$. In Expt 5, oocytes were washed twice with embryo culture medium $6-7 \mathrm{~h}$ after insemination and the group of 5-10 oocytes was transferred to a drop of embryo culture medium $(0.1 \mathrm{ml})$. Oocytes were cultured for $18 \mathrm{~h}$ or $42 \mathrm{~h}$ after insemination.

\section{Assessment for maturation, fertilization and cleavage}

Oocytes ( $18 \mathrm{~h}$ after insemination) and embryos ( $42 \mathrm{~h}$ after insemination) were fixed with methanol and acetic acid $(3: 1, \mathrm{v} / \mathrm{v})$ and stained with $1 \%$ aceto-orcein. The stages of oocytes and embryos were determined by a Nomarski 


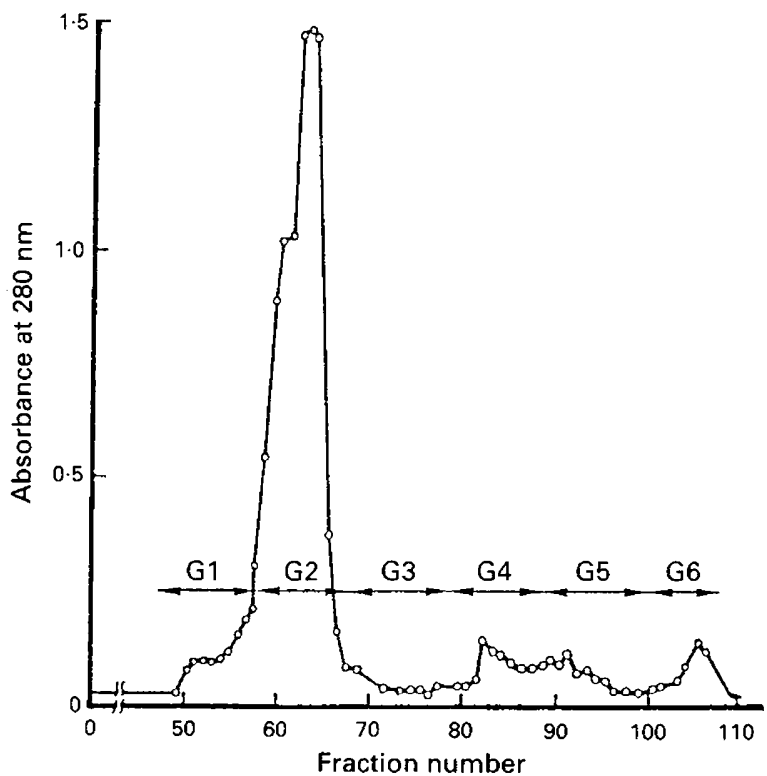

Fig. 1. Gel filtration (Toyopearl 55S) of pig follicular fluid $\left(10000<M_{\mathrm{r}}<200000\right)$ in Dulbecco's phosphate-buffered saline (PBS). Absorbances at $280 \mathrm{~nm} \mathrm{(o)}$ are given. Fractions of $1.5 \mathrm{ml}$ were collected at $4^{\circ} \mathrm{C}$ and pooled as indicated (G1-G6).

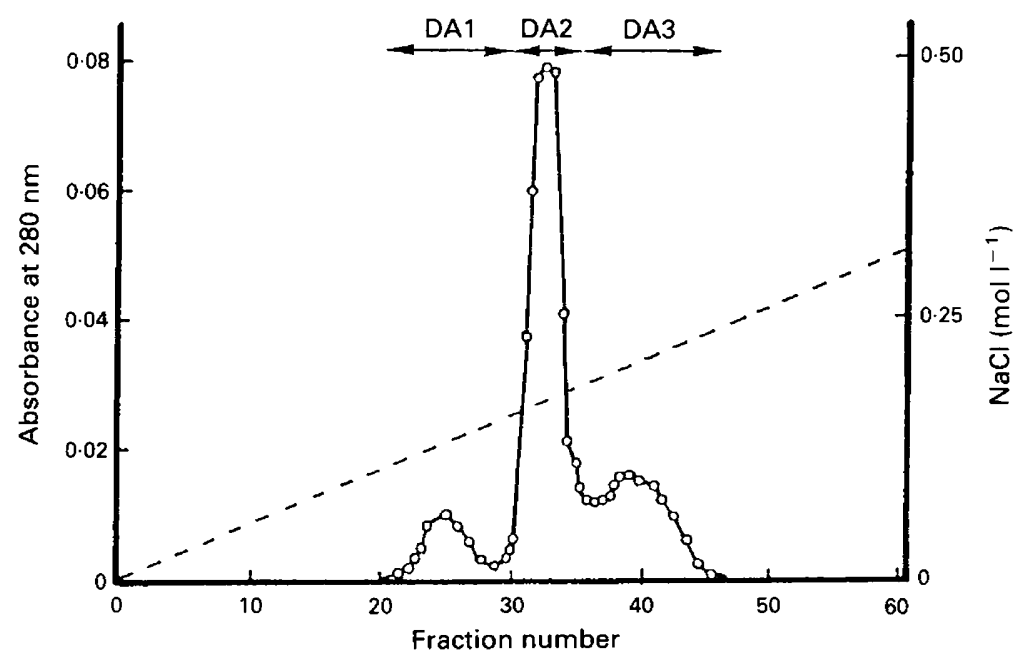

Fig. 2. Ion-exchange chromatography (DEAE-Toyopearl) of G1 obtained by gel filtration in $10 \mathrm{mmol}$ phosphate buffer $1^{-1}, \mathrm{pH} 6 \cdot 1$. Absorbance at $280 \mathrm{~nm}(\circ)$ and concentration of $\mathrm{NaCl}$ $(--)$ are given. Fractions of $2 \cdot 0 \mathrm{ml}$ were collected at $4^{\circ} \mathrm{C}$ and pooled as indicated (DA1-DA3).

differential interference microscope (Olympus): oocytes with a polar body were regarded as matured; oocytes with a female pronucleus with the enlarged sperm head or male pronucleus with sperm tail were regarded as fertilized. Polygynic fertilization was defined as fertilized oocytes with two or more female pronuclei. Polyspermic fertilization was defined as fertilized oocytes having two or more sperm heads or male pronuclei or two or more of both. Normal fertilization was defined as fertilized oocytes having two polar bodies and one set of male and female pronuclei. Normal cleavage of embryos (2-4 cells) was defined as cleaved embryos having blastomeres of regular size, two polar bodies and one nucleus in each blastomere. 


\section{Culture media and culture conditions}

The basic medium (medium B) consisted of $90 \%$ (v/v) TCM-199 with Earle's salt (Nissui Pharmaceutical Co., Tokyo, Japan) supplemented with $100 \mathrm{mg}$ sodium pyruvate $\mathrm{l}^{-1}$ (Sigma), $550 \mathrm{mg}$ glucose $\mathrm{l}^{-1}$ (Wako), $900 \mathrm{mg}$ calcium lactate $1^{-1}$ (Nakarai), $100 \mathrm{mg}$ dibekacin sulfate $1^{-1}$ (Meiji) and $10 \%(\mathrm{v} / \mathrm{v})$ fetal calf serum (FCS; GIBCO, Grand Island, NY, USA). The pH of medium B after equilibration with $5 \% \mathrm{CO}_{2}$ in air was $7 \cdot 4$. Medium $\mathrm{B}$, adjusted to $\mathrm{pH} 7 \cdot 8$, was used for sperm preincubation and medium $\mathrm{B}$ supplemented with 10 iu pregnant mares' serum gonadotrophin $\mathrm{ml}^{-1}$ (Teikoku Zoki Co., Tokyo, Japan), 10 iu human chorionic gonadotrophin $\mathrm{ml}^{-1}$ (Teikoku Zoki) and $1 \mu \mathrm{g}$ oestradiol ml $\mathrm{ml}^{-1}\left(\mathrm{E}_{2}\right.$ : Sigma) was used for maturation. In all experiments, the concentration of pig follicular fluid or its fractions added to maturation medium was $10 \%(\mathrm{v} / \mathrm{v})$. Medium B supplemented with $2 \mathrm{mmol}$ caffeine $\mathrm{I}^{-1}$ (Wako) was used for fertilization. Embryo culture medium consisted of $90 \%$ (v/v) TCM-199 with Earl's salt supplemented with $40 \mathrm{mg}$ sodium pyruvate $\mathrm{l}^{-1}, 3 \cdot 7 \mathrm{ml}$ sodium lactate $\mathrm{l}^{-1}$ (60\% syrup; Sigma), $100 \mathrm{mg}$ dibekacin sulfate $\mathrm{l}^{-1}$ and $10 \%(\mathrm{v} / \mathrm{v}) \mathrm{FCS}$. Maturation, fertilization and embryo culture in vitro were performed at $38.5^{\circ} \mathrm{C}$ in an atmosphere of $5 \% \mathrm{CO}_{2}$ in air. The handling of oocytes and embryos under the microscope was performed at $38^{\circ} \mathrm{C}$ on a heated stage (Kitazato Supply Co., Tokyo, Japan).

\section{Statistical analysis}

Experiments 1, 2,3, 4 and 5 were repeated three, five, five, five and six times, respectively, and data from each experiment were pooled. In each experiment, oocytes were allocated equally among the experimental groups. The statistical significance of the results was evaluated by the $\chi^{2}$ test with the Yates correction for continuity and by Fisher's exact test.

\section{Results}

\section{Experiment 1}

The effects of untreated, heated or defatted pig follicular fluid on maturation and fertilization of pig oocytes in vitro were examined. When pig follicular fluid or defatted pig follicular fluid was added to the maturation medium, the rates of cumulus expansion and nuclear maturation of oocytes were significantly higher $(P<0.01)$, and the rate of polygynic fertilization was significantly lower $(P<0.01)$ than the rates for oocytes in the medium without follicular fluid (control) (Table 1). However, the efficacy was lost after heating at $56^{\circ} \mathrm{C}$ for $30 \mathrm{~min}$.

Table 1. Effects of pig follicular fluid (pFF), heated $p F F$ and defatted $p F F$ on maturation and fertilization of pig oocytes in vitro

\begin{tabular}{lcllccc}
\hline & \multicolumn{5}{c}{ Number $(\%)$ of oocytes } \\
\cline { 2 - 7 } Addition & $\begin{array}{c}\text { Cumulus } \\
\text { expansion }\end{array}$ & $\begin{array}{c}\text { Nuclear } \\
\text { maturation }\end{array}$ & Fertilization & $\begin{array}{c}\text { Polygynic } \\
\text { fertilization }\end{array}$ & $\begin{array}{c}\text { Polyspermic } \\
\text { fertilization }\end{array}$ & $\begin{array}{c}\text { Male pronucleus } \\
\text { formation }^{2}\end{array}$ \\
\hline Control & $58 / 80(73)$ & $51 / 77(66)$ & $69 / 77(90)$ & $12 / 69(17)$ & $58 / 69(84)$ & $35 / 69(51)$ \\
pFF & $76 / 80(95)^{* *}$ & $69 / 77(90)^{* *}$ & $63 / 77(82)$ & $2 / 63(3)^{* *}$ & $46 / 63(73)$ & $37 / 63(59)$ \\
Heated pFF & $78 / 80(98)^{* *}$ & $63 / 80(79)$ & $71 / 80(89)$ & $15 / 71(21)$ & $50 / 71(70)$ & $37 / 71(52)$ \\
Defatted pFF & $77 / 85(91)^{* *}$ & $71 / 82(87)^{* *}$ & $68 / 82(84)$ & $4 / 82(5)^{* *}$ & $62 / 82(76)$ & $35 / 82(43)$ \\
\hline
\end{tabular}

${ }^{2}$ In oocytes fertilized.

${ }^{* *} P<0.01$ compared with the control value.

\section{Experiment 2}

The effects of fractions of pig follicular fluid obtained by ultrafiltration on maturation and fertilization of pig oocytes in vitro (Table 2) showed that, although the rate of cumulus expansion in the medium with UF1 was significantly higher $(P<0.01)$ than that in the control medium, the effect of pig follicular fluid was observed only in the medium with UF2. 
Table 2. Effects of fractions of pig follicular fluid (pFF) obtained by ultrafiltration on maturation and fertilization of pig oocytes in vitro

\begin{tabular}{|c|c|c|c|c|c|c|}
\hline \multirow[b]{2}{*}{ Addition $^{\mathbf{a}}$} & \multicolumn{6}{|c|}{ Number $(\%)$ of oocytes } \\
\hline & $\begin{array}{l}\text { Cumulus } \\
\text { expansion }\end{array}$ & $\begin{array}{l}\text { Nuclear } \\
\text { maturation }\end{array}$ & Fertilization & $\begin{array}{l}\text { Polygynic } \\
\text { fertilization }^{\mathrm{b}}\end{array}$ & $\begin{array}{l}\text { Polyspermic } \\
\text { fertilization }^{\mathrm{b}}\end{array}$ & $\begin{array}{l}\text { Male pronucleus } \\
\text { formation }^{\mathrm{b}}\end{array}$ \\
\hline Control & $85 / 148(57)$ & $99 / 145(68)$ & $97 / 145(67)$ & $21 / 97 \quad(22)$ & $75 / 97$ & $52 / 97 \quad(54)$ \\
\hline UF1 & $133 / 147(90)^{* *}$ & $109 / 147(74)$ & $101 / 147(69)$ & $21 / 101(21)$ & $65 / 101(64)$ & $42 / 101(42)$ \\
\hline UF2 & $135 / 145(93)^{* *}$ & $138 / 145(95)^{* *}$ & $108 / 145(74)$ & $6 / 108(6)^{* *}$ & $67 / 108(62)$ & $72 / 108(67)$ \\
\hline UF3 & $125 / 180(69)$ & $94 / 160(59)$ & $125 / 160(78)$ & $35 / 125(28)$ & $99 / 125(79)$ & $26 / 125(21)^{* *}$ \\
\hline
\end{tabular}

${ }^{\mathrm{a}} \mathrm{UFl}$ : pFF fraction obtained as concentrate with UK-200 $\left(M_{\mathrm{r}}>200000\right)$; UF2: pFF fraction obtained as concentrate with PM-10 of filtrate with UK-200 (10000 $\left.<M_{\mathrm{r}}<200000\right)$; UF3: pFF fraction obtained as filtrate with PM-10 $\left(M_{\mathrm{r}}<10000\right)$.

${ }^{b}$ In oocytes fertilized.

${ }^{* *} P<0.01$ compared with the control value.

\section{Experiment 3}

This experiment examined the effects of fractions of pig follicular fluid obtained by gel filtration on maturation and fertilization of pig oocytes in vitro. The efficacy of pig follicular fluid was found only in the medium with Gl (first eluted fraction) (Table 3).

Table 3. Effects of fractions of pig follicular fluid ( $\mathrm{pFF}$ ) obtained by gel filtration on maturation and fertilization of pig oocytes in vitro

\begin{tabular}{|c|c|c|c|c|c|c|}
\hline \multirow[b]{2}{*}{ Fraction $^{a}$} & \multicolumn{6}{|c|}{ Number $(\%)$ of oocytes } \\
\hline & $\begin{array}{l}\text { Cumulus } \\
\text { expansion }\end{array}$ & $\begin{array}{l}\text { Nuclear } \\
\text { maturation }\end{array}$ & Fertilization & $\begin{array}{l}\text { Polygynic } \\
\text { fertilization }^{\mathrm{b}}\end{array}$ & $\begin{array}{l}\text { Polyspermic } \\
\text { fertilization }^{b}\end{array}$ & $\begin{array}{l}\text { Male pronucleus } \\
\text { formation }^{\mathrm{b}}\end{array}$ \\
\hline Control & $128 / 172(74)$ & $119 / 171(70)$ & $130 / 171(76)$ & $34 / 130(26)$ & $85 / 130(65)$ & $58 / 130(45)$ \\
\hline Gl & $156 / 171(91)^{* *}$ & $148 / 171(87)^{* *}$ & $110 / 171(64)$ & $7 / 110(6)^{* *}$ & $54 / 110(49)^{*}$ & $74 / 110(67)^{* *}$ \\
\hline G2 & $117 / 171(68)$ & $117 / 167(70)$ & $117 / 167(70)$ & $24 / 117(21)$ & $51 / 117(44)^{* *}$ & $42 / 117(36)$ \\
\hline G3 & $135 / 170(79)$ & $125 / 166(75)$ & $118 / 166(71)$ & $19 / 118(16)$ & $63 / 118(53)$ & $50 / 118(42)$ \\
\hline G4 & $85 / 128(66)$ & $84 / 127(66)$ & $85 / 127(67)$ & $22 / 85 \quad(26)$ & $43 / 85 \quad(51)^{*}$ & $23 / 85(27)^{*}$ \\
\hline G5 & $78 / 128(61)$ & $82 / 127(65)$ & $67 / 127(53)$ & $17 / 67 \quad(25)$ & $29 / 67(43)^{*}$ & $19 / 67(28)^{*}$ \\
\hline G6 & $69 / 128(54)$ & $74 / 126(59)$ & $79 / 126(63)$ & $22 / 79$ & $39 / 79(49)^{*}$ & $31 / 79 \quad(39)$ \\
\hline
\end{tabular}

${ }^{\mathrm{a}} \mathrm{G}$ 1-G6: pFF fraction obtained by gel filtration.

bIn oocytes fertilized.

${ }^{*} P<0.05$ compared with the control value; ${ }^{* *} P<0.01$ compared with the control value.

\section{Experiment 4}

This experiment examined the effects of fractions of pig follicular fluid obtained by ionexchange chromatography on maturation and fertilization of pig oocytes in vitro. The efficacy of pig follicular fluid was found only in the medium with DA3 (third eluted fraction) (Table 4).

\section{Experiment 5}

This experiment examined the effects of pig follicular fluid and fractions of this fluid (UF2 and DA3) on the developmental capacity of pig oocytes matured and fertilized in vitro (Table 5). The rates of nuclear maturation and normal fertilization in the medium with pig follicular fluid or its fractions were significantly higher than those in the control medium $18 \mathrm{~h}$ after insemination 
Table 4. Effects of fractions of pig follicular fluid (pFF) obtained by ion-exchange chromatography on maturation and fertilization of pig oocytes in vitro

\begin{tabular}{lcccccc}
\hline & \multicolumn{7}{c}{ Number (\%) of oocytes } \\
\cline { 2 - 7 } Fraction $^{\mathrm{a}}$ & $\begin{array}{c}\text { Cumulus } \\
\text { expansion }\end{array}$ & $\begin{array}{c}\text { Nuclear } \\
\text { maturation }\end{array}$ & Fertilization & $\begin{array}{c}\text { Polygynic } \\
\text { fertilization }^{\mathrm{b}}\end{array}$ & $\begin{array}{c}\text { Polyspermic } \\
\text { fertilization }^{\mathrm{b}}\end{array}$ & $\begin{array}{c}\text { Male pronucleus } \\
\text { formation }^{\mathrm{b}}\end{array}$ \\
\hline Control & $108 / 177(61)$ & $122 / 177(69)$ & $137 / 177(77)$ & $41 / 137(30)$ & $96 / 137(70)$ & $59 / 137(43)$ \\
DA1 & $71 / 175(41)$ & $114 / 175(65)$ & $77 / 175(44)^{* *}$ & $14 / 77(18)$ & $19 / 77(25)^{* *}$ & $17 / 77(22)^{* *}$ \\
DA2 & $119 / 176(68)$ & $121 / 176(69)$ & $99 / 176(56)^{* *}$ & $16 / 99(16)$ & $61 / 99(62)$ & $39 / 99(39)$ \\
DA3 & $164 / 176(93)^{* *}$ & $157 / 176(89)^{* *}$ & $133 / 176(76)$ & $7 / 133(5)^{* *}$ & $74 / 128(58)^{*}$ & $89 / 133(67)^{* *}$ \\
\hline
\end{tabular}

${ }^{a}$ DA1-DA3: pFF fraction obtained by ion-exchange chromatography.

bIn oocytes fertilized.

${ }^{*} P<0.05$ compared with the control value; ${ }^{* *} P<0.01$ compared with the control value.

$(P<0.01)$. At $42 \mathrm{~h}$ after insemination, the rate of cleavage of embryos derived from oocytes matured in the presence of pig follicular fluid or its fractions did not differ from that in the controls. However, the rate of normal cleavage of embryos derived from oocytes matured in the presence of pig follicular fluid or its fractions was significantly higher than that in the controls $(P<0.01)$.

Table 5. Effects of pig follicular fluid (pFF) and pFF fractions obtained by ultrafiltration or ion-exchange chromatography on developmental capacity of pig oocytes matured and fertilized in vitro

\begin{tabular}{|c|c|c|c|c|c|}
\hline \multirow[b]{3}{*}{ Fraction $^{a}$} & \multicolumn{3}{|c|}{ Number $(\%)$ of oocytes } & \multicolumn{2}{|c|}{ Number $(\%)$ of embryos } \\
\hline & \multicolumn{3}{|c|}{$18 \mathrm{~h}$ after insemination } & \multicolumn{2}{|c|}{$42 \mathrm{~h}$ after insemination } \\
\hline & $\begin{array}{l}\text { Nuclear } \\
\text { maturation }\end{array}$ & Fertilization & $\begin{array}{c}\text { Normal } \\
\text { fertilization }\end{array}$ & Cleavage & $\begin{array}{l}\text { Normal } \\
\text { cleavage }^{\mathrm{c}}\end{array}$ \\
\hline Control & $46 / 70 \quad(66)$ & $40 / 70 \quad(57)$ & $3 / 40 \quad(8)$ & $107 / 220(49)$ & $14 / 107(13)$ \\
\hline pFF & $92 / 101(91)^{* *}$ & $68 / 101(67)$ & $24 / 68(35)^{* * *}$ & $103 / 192(54)$ & $30 / 103(29)^{* *}$ \\
\hline UF3 & $66 / 77(86)^{* *}$ & $41 / 77 \quad(53)$ & $14 / 41(34)^{* * *}$ & $114 / 220(52)$ & $33 / 114(29)^{* *}$ \\
\hline DA3 & $62 / 70 \quad(89)^{* *}$ & $35 / 70 \quad(50)$ & $14 / 35(40)^{* *}$ & $105 / 220(48)$ & $42 / 105(40)^{* *}$ \\
\hline
\end{tabular}

${ }^{a}$ UF3: pFF fraction obtained as filtrate with PM-10 $\left(M_{\mathrm{r}}<10000\right)$; DA3: pFF fraction obtained by ionexchange chromatography.

bIn oocytes fertilized.

'In cleaved embryos.

${ }^{* *} P<0.01$ compared with the control values.

\section{Discussion}

The results of this study show that pig follicular fluid contains a substance(s) that improves the rate of cumulus expansion, nuclear maturation, normal fertilization and normal development. The fractionation data indicate that this activator is partially purified by ultrafiltration, gel filtration and ion-exchange chromatography and appears to be an acidic substance(s) with a molecular weight between 10000 and 200000 . The chromatographic data showed that the activity was observed in only one fraction, suggesting that the efficacy of pig follicular fluid does not result from the synergistic effect of several substances. The activity was detected in the first fraction (G1) obtained by gel filtration, suggesting that the molecular weight of this substance(s) was of the order of tens of thousands. Westergaard et al. (1984) demonstrated that human follicular fluid contained a substance that induces meiosis; this substance had the characteristics of a lipid with a molecular 
weight $<5000$, and promoted the onset of meiosis in germ cells of mouse fetuses. With respect to characteristics and molecular weight, the substance(s) detected in pig follicular fluid in this study is different from that reported in human follicular fluid. However, addition of pig follicular fluid to maturation medium is effective on maturation of mouse (Eppig \& Schroeder, 1986) and pig oocytes (Naito et al., 1988) in vitro. Although our results confirm the previous study, the efficacy of pig follicular fluid observed in this study is different, since oocytes were found to form male pronuclei after in vitro fertilization (Naito et al., 1988). Namely, the efficacy of pig follicular fluid on nuclear maturation is greater than that on male pronuclei formation in this study. The reason for this is unclear, but might be due to the differences between the conditions of culture (e.g. the duration of culture and the type of medium), the concentration of pig follicular fluid added to the medium $(10 \%$ versus $100 \%)$ and the substance(s).

In culture of immature pig oocytes in vitro, the time required for nuclear maturation varies among oocytes (Sato et al., 1978; Yoshida et al., 1989) and the occurrence of chromosomal abnormalities such as diploid nucleus is high (McGaughey \& Polge, 1971). In addition, the occurrence of polygyny is due to the fertilization of immature or aged oocytes (Bedford, 1982) and polygyny results from failure of the first or second polar body to extrude (Xu \& Greve, 1988). It is therefore possible that pig follicular fluid effectively prevents those defects during culture in vitro and this results in a supply of healthy oocytes to achieve the normal fertilization and development after fertilization in vitro seen in this study: it is probable that pig follicular fluid was effective in regulating or accelerating the time of polar body emission and resulted in a high frequency of fertilized pig embryos subsequent to the two-cell to four-cell stage.

However, it is reported that glycosaminoglycans isolated from bovine or pig follicular fluid increased the viability of mouse and pig oocytes (Sato et al., 1987, 1990). Glycosaminoglycans are heat stable $\left(60^{\circ} \mathrm{C}\right.$ for $\left.24 \mathrm{~h}\right)$, but the efficacy of pig follicular fluid detected in this study was lost after heating (Expt 1), indicating that the substance(s) from pig follicular fluid in this study is not a glycosaminoglycan. The effect of pig follicular fluid on cumulus expansion was maintained after heating and observed in the fraction with molecular weight $>200000$, whereas that for nuclear maturation was lost after heating. Since the addition of substrates for hyaluronic acid synthesis to maturation medium enhances the cumulus expansion of mouse oocytes in vitro (Chen et al., 1990), pig follicular fluid contains several substrates that enhance cumulus expansion of pig oocyte cumulus complexes. However, it is unlikely that cumulus expansion promotes the viability of pig oocytes and that this results in nuclear maturation, because the increasing rates of cumulus expansion do not correlate with the enhancement of nuclear maturation.

In conclusion, these results indicate that pig follicular fluid has beneficial effects on maturation of oocytes in vitro and on the production of embryos after fertilization in vitro. However, further studies are necessary to identify the substance(s) in pig follicular fluid and clarify its mechanism of action on oocyte maturation.

We thank Y. Kuwahara for supplying the boar semen, and the staff of the Meat Inspection Center, City of Shizuoka, for supplying the pig ovaries. This work was partly supported by a grant from the Ito Foundation.

\section{References}

Bedford, J.M. (1982) In Reproduction in Mammals: Germ Cell and Fertilization, pp. 128-163. Eds C. R. Austin \& R. V. Short, Cambridge University Press, Cambridge.

Chen, L., Wert, S.E., Hendric, E.M., Russell, P.T., Cannon, M. \& Larsen, W.J. (1990) Hyaluronic acid synthesis and gap junction endocytosis are necessary for normal expansion of the cumulus mass. Molecular Reproduction and Development 26, 236-247.
Eppig, J.J. \& Schroeder, A.C. (1986) Culture systems for mammalian oocyte development: progress and prospects. Theriogenology 25, 87-96.

McGaughey, R.W. \& Polge, C. (1971) Cytogenetic analysis of pig oocytes matured in vitro. Journal of Experimental Zoology 176, 383-396.

Mattioli, M., Bacci, M.L., Galeuti, G. \& Seren, E. (1989) Developmental competence of pig oocytes matured and fertilized in vitro. Theriogenology 31, 1201-1207. 
Nagai, T., Takahashi, T., Shioya, Y. \& Oguri, N. (1990) Maturation and fertilization of pig follicular oocytes cultured in pig amniotic fluid. Theriogenology 34, 195-204.

Naito, K., Fukuda, Y. \& Toyoda, Y. (1988) Effects of porcine follicular fluid on male pronucleus formation in porcine oocytes matured in vitro. Gamete Research 21, 289-295.

Sato, E., Iritani, A. \& Nishikawa, Y. (1978) Rate of maturation division of pig follicular oocytes cultured in vitro. Japanese Journal of Zootechnology Science 49, $400-405$.

Sato, E., Ishibashi, T. \& Koide, S.S. (1987) Prevention of spontaneous degeneration of mouse oocytes in culture by ovarian glycosaminoglycans. Biology of Reproduction. 37, 371-376.

Sato, E., Miyamoto, H. \& Koide, S.S. (1990) Glycosaminoglycans in porcine follicular fluid promoting viability of oocytes in culture. Molecular Reproduction and Development 26, 391-397.

Stone, S.L., Promerantz, S.H., Schwartz-Kripner, A. \& Channing, C.P. (1978) Inhibitor of oocyte maturation from porcine follicular fluid: further purification and evidence for reversible action. Biology of Reproduction 19, 585-592.

Tsafriri, A. \& Channing, C.P. (1975) An inhibitory influence of granulosa cells and follicular fluid upon porcine oocyte meiosis in vitro. Endocrinology 96, 922-927.

Tsafriri, A., Dekel, N. \& Bar-Ami, S. (1982) The role of oocyte maturation inhibitor in follicular regulation of oocyte maturation. Journal of Reproduction and Fertility 64, 541-551.

Westergaard, L., Byskov, A.G., Anderson, G.Y., Grinsted, J. \& McNatty, K.P. (1984) Is resumption of meiosis in the human preovulatory oocyte triggered by a meiosis-inducing substance (MIS) in the follicular fluid? Fertility and Sterility 41, 377-384.

Whittingham, D.G. (1971) Survival mouse embryos after freezing and thawing. Nature 233, 125-126.

Xu, K.P. \& Greve, T. (1988) A detailed analysis of early events during in-vitro fertilization of bovine follicular oocytes. Journal of Reproduction and Fertility 82, $127-134$.

Yoshida, M., Bamba, K. \& Kojima, Y. (1989) Effects of gonadotropins and estradiol-17 $\beta$ on the timing of nuclear maturation and cumulus mass expansion in pig oocytes cultured in vitro. Japanese Journal of Animal Reproduction 35, 86-91.

Yoshida, M., Ishizaki, Y. \& Kawagishi, H. (1990) Blastocyst formation by pig embryos resulting from in-vitro fertilization of oocytes matured in vitro. Journal of Reproduction and Fertility 88, 1-8.

Received 2 April 1991 